\title{
Entrevista a Vani Moreira Kenski
}

Mônica Ferreira Mayrink

Lívia Márcia Tiba Rádis Baptista

Vani Moreira Kenski

Doutora em Educação pela UNICAMP. Professora do Programa de Pós-Graduação em Educação da Faculdade de Educação/ USP. Pesquisadora na área de Educação a Distância; Ensino mediado pelas tecnologias digitais e Educação, comunicação e tecnologias digitais. Autora dos livros: Tecnologias e ensino presencial e a distância; Educação e Tecnologias: o novo ritmo da informação e Tecnologias e tempo docente, todos pela ed. Papirus. Autora e organizadora do livro Design Instrucional para cursos online (Editora SENAC/SP).

Contato: vani@siteeducacional.com.br

Mônica Ferreira Mayrink

Doutora e Mestre em Lingüistica Aplicada e Estudos da Linguagem pela Pontifícia Universidade Católica de São Paulo. Professora da Graduação e Pós-Graduação no Departamento de Letras Modernas da Faculdade de Filosofia, Letras e Ciências Humanas da USP. Tem experiência na área de Linguística Aplicada, com ênfase nos seguintes temas: formação de professores, reflexão, ensino $e$ aprendizagem de línguas presencial e a distância.

Contato: momayrink@usp.br

Lívia Márcia Tiba Rádis Baptista

Doutora em Linguística pela UNICAMP e Mestre em Letras e em Educação, ambos pela Universidade de São Paulo. Professora do Departamento de Letras Românicas da Universidade Federal da Bahia. Atua nos programas de Pós-Graduação em Linguística da UFC e no de Pós-Graduação em Língua e Cultura da UFBA. Tem experiência na área de Linguística Aplicada, principalmente nos seguintes temas: ensino e aprendizagem de

Recebido em: 28 de novembro de 2016 línguas e formação de professores.

Aceito em: 14 de dezembro de 2016 Contato: liviarad@yahoo.com 
CARACOL: Muito se fala sobre o impacto das tecnologias no ensino na atualidade. Como você caracteriza esse cenário?

VAni Moreira Kenski: As mudanças incorporadas à sociedade pelas tecnologias digitais chegam muito lentamente à educação. Neste caso, estou considerando a educação formal, legalmente instituída. Isto porque a educação informal - aberta e livre - tem, nos usuários conectados nos mais diferenciados dispositivos digitais, a sua principal tribo.

Idade, localização física, formação escolar... as designações que identificam os seres em uma instituição de ensino regular, nas ações educacionais livres via internet não são tão relevantes. Isto faz diferença e causa um dos principais impactos na atualidade, ou seja, para aprender não é preciso ir para a escola.

Seres conectados com vontade de aprender, aprendem. As ofertas são abertas, amplas, livres, transnacionais e, na maioria das vezes, gratuitas. Interligadas nas redes, as conexóes entre mentes (Kerckhove, 2009) - e entre estas e a infinidade de dados disponíveis e acessáveis - libertam as pessoas da dependência do acesso à informação e ao conhecimento apenas pelos caminhos formais e legais do ensino regular. Como diz Michel Serres (2015), "o acesso à informação mudou completamente o jogo do ensino". O fácil acesso à informação disponibilizada pelos meios digitais transforma as práticas e a pedagogia.

CARACOL: Em que medida você acha que esse movimento se aplica ao contexto brasileiro?

vMK: A revolução digital já existe no Brasil, independente dos problemas de infraestrutura tecnológica, baixa velocidade de banda, monopólios 
comerciais e legislação defasada que temos e que prejudicam o amplo acesso e uso das tecnologias digitais, sobretudo a internet.

O Brasil possui hoje presença significativa de usuários na internet. No ranking mundial ocupa a quinta posição em número de usuários logados, perdendo apenas para China, Estados Unidos, Índia e Japão. Dados bem atuais mostram que o país representa $40 \%$ de todo o contingente online da América Latina. Isto, no entanto, não basta. Em termos de contexto brasileiro, o país ainda sofre de um gap significativo de exclusão digital.

$\mathrm{Na}$ realidade digital brasileira o que fica evidente é a desigualdade nas condiçóes de acesso e uso dos recursos e dispositivos disponíveis na internet pelo território brasileiro. Temos espaços diferenciados, sobretudo no Sul e no Sudeste, com níveis ótimos de presença digital. Outras partes do Brasil (e mesmo regióes e bairros do mesmo estado ou cidade) não possuem condições mínimas de acesso e fraco conhecimento para uso dos meios digitais. Esta desigualdade replica as desigualdades econômicas e educacionais existentes em todo o país. Ou seja, na nossa realidade brasileira, a internet é elitista, colabora para a divisão social (entre os que têm ou não acesso), é cara, de baixa qualidade e garante precariamente as condiçôes para viabilização de projetos educacionais online extensivos.

Se fecharmos as nossas lentes para o contexto educacional do ensino superior brasileiro teremos um grupo mais homogêneo em relação ao acesso e uso das tecnologias digitais. Neste grupo o uso da internet é ampliado com finalidades de comunicação, entretenimento, acesso à informação e aprendizagens. Neste contexto, o uso da Internet para realização de trabalhos e pesquisas é intenso. A oferta ampliada de dados facilita a busca de 
informações. As possibilidades de interações viabilizam a formação de redes de pessoas com vontade de aprender, pesquisar, avançar no conhecimento... independente do espaço em que se encontrem. Neste segmento predomina o uso das tecnologias para aprender, em instituiçóes de ensino ou de forma aberta e livre.

CARACOL: Podemos afirmar que o perfil do professor no século XXI já mudou? E o perfil do aluno, já é outro? Por quê?

vMK: Professores e alunos - sobretudo os do ensino superior - estão naturalmente integrados à cultura digital. Acessam internet, usam celulares e adquirem práticas ligadas ao uso dos dispositivos digitais. Este perfil pessoal não se descola totalmente do perfil profissional - de professor ou de aluno que representam nos espaços educacionais, ainda que nestes espaços não se utilizem diretamente dos meios digitais para ensinar e aprender.

CARACOL: Que avanços teórico-metodológicos são necessários para uma integração mais eficaz das TIC na educação?

VMK: Acredito que não são necessariamente avanços, mas fazer o que Dewey já dizia há 100 anos e que nunca foi compreendido integralmente e posto em prática como deveria. Ou seja, significa colocar ênfase na experimentação e no trabalho colaborativo como posicionamentos metodológicos essenciais. Ou seja, aprender fazendo. Praticar, se expor, explorar em grupos, refletir sobre os resultados e descobertas e ir além, continuamente. Promover a criação, a investigação e a originalidade no processo de ensino-aprendizagem. Buscar soluçôes criativas e saber aproveitar os recursos disponíveis. Teóricos 
como George Siemens, Eric Mazur, Jane Lave, para citar alguns, propóem caminhos para a integração das pessoas mediadas pelos dispositivos digitais e que convergem para estes mesmos princípios. Importante, portanto, é a integração entre as pessoas e o uso dos recursos digitais para viabilizar esta possibilidade de aprender e ensinar, juntos.

CARACOl: Considerando esse cenário, que demandas ou desafios se apresentam para as instituiçóes de ensino superior formadoras de professores?

vMK: As possibilidades de uso massivo e intenso da internet requerem mudanças estruturais nos programas, currículos, ações didáticas e funcionamento das escolas de todos os níveis.

Os cursos de formação de professores precisam se abrir para o presente e alterarem significativamente seus modelos de formação. Abrirem-se para práticas de ensino mediadas. Isto exige alterações não apenas nos conteúdos e nas formas de ensino presenciais, mas nas temporalidades das aulas e na atuação dos professores.

É preciso tempo para que se possa realizar buscas online, planejamento, preparação e organização das aulas. Tempo para as açôes e para interações online. Elaboração e participação em projetos colaborativos com professores e alunos de outras áreas que possibilitem interfaces em que todos aprendam.

$\mathrm{O}$ êxito dessas iniciativas é diretamente proporcional à frequência das interaçóes didático-comunicativas entre todos os envolvidos, à liderança do mediador e ao trabalho colaborativo realizado por todos os participantes das equipes de professores e alunos.

Enquanto os cursos de formação de professores continuarem praticando o ensino para o passado - vivenciando currículos focados no mundo da certeza 
e no tempo analógico dos processos educacionais dos séculos anteriores-, não teremos bons professores que consigam dialogar com as necessidades da realidade educacional e social da atualidade.

Em um texto ${ }^{1}$ anterior, eu já havia dito que

O futuro da educação no Brasil, assim como em todo o mundo, se orienta basicamente pelas inovaçôes apresentadas na internet. Não há como definir - na realidade econômica e educacional do Brasil, neste momento - o que será concretizado, mas é possível vislumbrar o necessário para a melhoria da qualidade da educação e como a internet pode colaborar para isto. Neste momento, uma conexão rápida e sem fio (wi-fi) e a nuvem já condicionam a possibilidade de mudanças radicais, para melhor, nas escolas.

CARACOL: Pensando na produção de materiais e conteúdos digitais para o ensino de línguas na escola básica, no seu modo de ver, como os pesquisadores podem contribuir?

vMK: Uma das principais iniciativas para os pesquisadores que se preocupam com a melhoria da qualidade do ensino na atualidade é a de conhecer a realidade. Ir ao encontro dos alunos e seus professores. Pesquisar suas necessidades e confrontá-las com o que as tecnologias podem oferecer para auxiliar e facilitar, no contexto em que se encontram. Importante também é não se isolar, integrar-se com pesquisadores em redes nacionais e internacionais que tenham objetivos de pesquisa comuns. Formar equipes

1 Educação e internet no Brasil. Cadernos Adenauer XVI. No.3. 2015. Disponível em: <http:// www.kas.de/wf/doc/16511-1442-5-30.pdf>. Acesso: 6/11/2016. 
interdisciplinares para o desenvolvimento de projetos que possam ir ao encontro dos desejos e necessidades atuais dos alunos, professores, escolas.

Como já disse, em outro texto ${ }^{2}$,

As novas formas de interação e comunicação em redes, oferecidas pelas mídias digitais, possibilitam a realização de trocas de informaçōes e cooperaçóes em uma escala inimaginável. Permitem o desenvolvimento de projetos colaborativos complexos e associações inesperadas e permitem a construção coletiva aberta.

Exemplos desta forma de ação integrada são apresentados em e-books, como Recursos Educacionais Abertos e Redes Sociais e Tecnologias Digitais para Produçáo do Conhecimento no Ciberespaço.

Pesquisadores em campo com professores, com projetos "mão na massa”, podem fazer muito e colaborar para que todos aprendam de forma satisfatória, de acordo com o contexto e a realidade atual. Um bom exemplo disto é descrito pela professora Dulce Cruz (UFSC) no artigo "RPG Maker como ferramenta pedagógica: produzindo jogos eletrônicos com crianças"3. É uma pesquisa acadêmica e um processo de intervenção utilizando software e narrativas. Fez diferença.

2 Educ. Soc., Campinas, vol. 29, n. 104 - Especial, p. 647-665, out. 2008647 Disponível em: <http://www.cedes.unicamp.br/>. Acesso: 6/11/2016.

3 Dulce Márcia Cruz. "RPG Maker como ferramenta pedagógica: produzindo jogos eletrônicos com crianças". Disponível em: <http://siaiap32.univali.br/seer/index.php/acotb/article/ view/6391/3620>. Acesso: 6/11/2016. 
CARACOL: Quais seriam os principais desafios e perspectivas para a formação de professores de línguas com respeito às estratégias de aprendizagem e de ensino no cenário tecnológico?

vMк: O principal desafio em relação a estratégias de ensino em qualquer curso ou processo formativo está na rigidez da estrutura das instituiçôes de ensino e na visão antiquada e preconceituosa (em relação ao uso das tecnologias digitais no ensino) de gestores e docentes. A insistência destes em manter o mesmo tipo de postura tradicional, inflexível e distante, focada no conteúdo a ser "entregue" aos alunos, sem maior interação e sem considerar as mudanças na cultura e na realidade social e educacional, inviabiliza qualquer projeto de ensino digitalmente mediado.

Em relação às estratégias de aprendizagem para a formação de professores de línguas, as perspectivas são inúmeras. Considerando que as redes digitais nos colocam em tempos e espaços em que proliferam os usos dos mais diversos idiomas, a criatividade do coletivo de professores e alunos pode criar estratégias diferenciadas em que todos aprendam. Propor projetos e desafios que possam entusiasmar os alunos a participarem, a serem agentes ativos para suas próprias aprendizagens, vale a pena.

Colaboração, construção coletiva, cocriação, atuação em equipes para a superação de desafios e alcance de resultados que beneficiem o aprendizado e garantam o aprendizado de todos, com suas diferenças e especificidades.

CARACOL: Pensando nas diversas competências, como se definiria a do professor de línguas em relação à tecnologia?Quais seriam os saberes 
necessários para esse professor no contexto da escola básica? Como os cursos de formação de professores podem contribuir?

vMK: Não posso dizer, especificamente, em relação aos professores de línguas, mas todos os professores precisam considerar a formação e capacitação dos docentes não apenas para uso das mídias digitais atuais. Isso eles já sabem e usam em seus tempos livres. É preciso que eles sejam formados para uma nova didática, uma nova pedagogia, que considere as alteraçóes disruptivas ocasionadas pela internet na maneira de ensinar, de se relacionar com os alunos e com o próprio conhecimento. Requer a compreensão das possibilidades das redes para chegar a todos os estudantes, indiscriminadamente e, dessa forma, alcançar a desejável universalização e democratização do acesso a educação de qualidade.

As tecnologias estão em permanente processo de atualização e transformação. Como diz Siemens, o criador do Conectivismo, "escolher o que aprender e o sentido da informação que nos chega é visto através da lente de uma realidade em permanente transformação. A resposta que agora é correta pode ser errada amanhã, devido a alteraçôes no clima informacional que afeta a decisão”.

De acordo com o Conectivismo, os modos como a pessoa aprende e atua no mundo foram alterados pelo uso dos novos recursos digitais. De acordo com este posicionamento teórico, a concepção de ensinar e aprender baseiase em alguns princípios essenciais. Alguns deles:

- A aprendizagem e o conhecimento baseiam-se na diversidade de opiniôes; 
- A aprendizagem é um processo de conectar nós especializados ou fontes de informação;

- A aprendizagem pode residir em dispositivos náo humanos;

- A capacidade de saber mais é mais importante do que aquilo que sabemos num determinado momento;

- Promover e manter conexóes é fundamental para facilitar a aprendizagem contínua.

- A capacidade de ver conexôes entre ideias, conceitos e áreas de saber é uma habilidade fundamental;

Sobre este assunto, considero importante ir direto à fonte, ou seja, ao livro do próprio George Siemens, CONECTIVISMO Uma Teoria de Aprendizagem para a Idade Digital.

Outras bibliografias interessantes para o aprofundamento e compreensão das possibilidades de atuaçáo dos professores na atualidade podem ser encontradas em dois livros bem atuais: Ensino híbrido: personalizaçáo e tecnologia da educaçáo, da Lilian Bacich e Transdisciplinaridade, Criatividade e Educaçáo: Fundamentos Ontológicos e Epistemológicos, da Maria Cândida Moraes. 